\title{
Successive sensory discriminative behavior maintained by forebrain self-stimulation
} \section{reinforcement*}

\author{
IRMINGARD I. LENZER† and GABRIEL P. FROMMER \\ Indiana University, Bloomington, Ind. 47401
}

Nine albino rats were trained on a CRF schedule to press a lever for electrical self-stimulation reward in the forebrain. They were then taught to discriminate between an $\mathbf{S}+$ (a white noise plus a light) that lasted until the animal made one reinforced leverpress and an $\mathrm{S}-$ (defined as the absence of the light and noise) that varied from $15 \mathrm{sec}$ to $16 \mathrm{~min}$ in duration. The duration of the $\mathrm{S}-$ interval did not affect the latency of the response to the $S_{+}^{+}$, except, in some cases, in the early stages of the learning of the discrimination. The results are discussed in terms of the drive-decay and the incentive models of rewarding brain stimulation.

In a previous study (Lenzer \& Frommer, 1968), we found that hypothalamic ESB (electrical stimulation of the brain) reward was able to maintain successive sensory discriminative behavior free of lability; neither the rate of responding during the $S+$ period nor the latency of the first leverpress following the $\mathrm{S}+$ onset was affected by increasing the duration of the $S-$ period, even to as long as $30 \mathrm{~min}$. Furthermore, priming was not necessary to start the animals responding to the $\mathrm{S}+$ at the beginning of the daily sessions, and the animals displayed an unexpectedly high resistance to extinction. This study and many others in recent years (Gandelman, Panksepp, \& Trowill, 1968; Gandelman \& Trowill, 1968; Gibson, Reid, Sokai, \& Porter, 1965; Kornblith \& Olds, 1968; Lenzer \& Frommer, 1968; Pliskoff, Wright, \& Hawkins, 1965; Scott, 1967; Trowill, Panksepp, \& Gandelman, 1969) indicate that lability, defined as the relatively rapid decline in response strength during periods when reinforcement is not obtainable, is not a general or unalterable property of behaviors maintained by ESB reinforcement; thus, the drive-induction and -decay theory proposed by Deutsch and others (Deutsch \& Howarth, 1963; Gallistel, 1964; Howarth \& Deutsch, 1962) is called into question. Trowill et al (1969) maintain that the paradoxical lability of ESB-reinforced behaviors stems from training procedures and not from any inherent features of ESB reinforcement. However, Scott's work (1967) suggests that stimulation site

*'This research was supported in part by National Institute of Mental Health Grants MH 10852 and MH 16046 to G. Frommer and in part by National Research Council of Canada Grant No. APA0380 to I. Lenzer.

tNow at Saint Mary's University, Halifax, Nova Scotia, Canada. may be a factor in determining the degree of lability. The purpose of the present study was to determine whether or not discrimination behavior maintained by forebrain ESB reward shows the same absence of lability as does behavior maintained by hypothalamic reward.

\section{METHOD}

Two separate experiments were run, separated in time by several months. The second was undertaken in an attempt to study more closely the effect of learning on lability, although it is reported here mainly because it yielded additional data on the main question of lability of discrimination behavior.

The apparatus used for these two experiments was the same as that used in the previous study (Lenzer \& Frommer, 1968). The S+ consisted of an amber light from a No. 313 lamp, set in an amber jewel 3 in. above the operant lever, together with white noise, coming from a white-noise source outside the experimental chamber and having a 63-dB SPL inside the chamber. The $\mathrm{S}-$ was defined to be the absence of the $S+$. The program controlling the stimulus events was designed so that, for the discrimination phases of the experiments (both learning and testing), the animal had to cease responding during the $S-$ period for at least $10 \mathrm{sec}$ before the scheduled onset of the S+; this was to facilitate the learning of the discrimination. Another feature of the program was that if the animal failed to respond to the $\mathrm{S}+$ within $60 \mathrm{sec}$ the $\mathrm{S}+$ was terminated.

The Ss for both experiments were male albino Wistar rats, about 100 days of age and weighing about $350 \mathrm{~g}$ at the beginning of the experiment. All animals received food and water ad lib throughout the experiment.
Permanent bipolar electrodes (Lenzer \& Frommer, 1968), aimed at right and left forebrain areas (coordinates: $3 \mathrm{~mm}$ anterior to bregma, $1 \mathrm{~mm}$ lateral to the midline of the skull, and $6.5 \mathrm{~mm}$ below the brain surface), were implanted in each animal under pentobarbital (Nembutal) anesthesia (50 $\mathrm{mg} / \mathrm{kg}$, IP).

Following a 3-day recovery period, each animal was trained to press a lever for ESB reward in the presence of the St. Following the initial shaping period, which lasted 1 or 2 days, each animal was kept on a CRF (continuous reinforcement) schedule for 3 days, each daily session lasting about $1 \mathrm{~h}$. The right or the left forebrain area, whichever yielded the higher rate of responding during this phase, was selected for study in the subsequent phases. Also during this CRF phase, the ESB parameters were fixed: The waveform was biphasic rectangular, the pulse width was $0.5 \mathrm{msec}$, the interval between the positive and the negative pulses of each pulse pair was $5 \mathrm{msec}$, there were 100 pulse pairs/second, the train duration was $300 \mathrm{msec}$, and the stimulus intensity was 1,000 microA for all animals. The ESBs were delivered through a constant-current source.

The animals were then taught to discriminate the $\mathrm{S}+$ from the $\mathrm{S}-$. For both experiments the $S+$ period lasted as long as it took the animal to make 31 leverpresses, each leverpress being reinforced with one ESB burst or train. For Experiment 1 the discrimination learning phase lasted from 5 to 7 days, each daily session lasting about $80 \mathrm{~min}$; the $\mathrm{S}-$ period was gradually increased in duration, from $15 \mathrm{sec}$ on the first day to $16 \mathrm{~min}$ on the last day. For Experiment 2 the discrimination learning phase was limited to 3 days, each session lasting about $70 \mathrm{~min}$, and the duration of the $S-$ period was kept at $15 \mathrm{sec}$; these changes from Experiment 1 to Experiment 2 were made in the hopes of placing a greater portion of the discrimination learning process in the "testing" phase of the experiment.

The animals in Experiment 1 were then presented with a random sequence of $\mathbf{S}+$ and $\mathrm{S}-$ intervals; the $S-$ intervals (15 sec, $30 \mathrm{sec}, 1 \mathrm{~min}$, $2 \mathrm{~min}, 4 \mathrm{~min}, 8 \mathrm{~min}$, and $16 \mathrm{~min}$ ) were varied randomly, with the restriction that each interval occur two times during each daily session. The "duration" of the S+ period was gradually reduced over a period of 2 to 4 days, from 31 reinforced leverpresses to 1 ; when the animal made the number of leverpresses called for, the S+ was terminated, and no further responses were reinforced until the next S+ period. The animals of Experiment 2 did not go through this 
Table 1

Mean Latency (in Seconds) of Response to $\mathbf{S}+$ as a Function of Preceding $\mathbf{S}$ - Duration

\begin{tabular}{|c|c|c|c|c|c|c|c|}
\hline \multirow[b]{2}{*}{ A nimal } & \multicolumn{7}{|c|}{ Preceding $\mathbf{S}-$ Duration } \\
\hline & $15 \mathrm{Sec}$ & $30 \mathrm{Sec}$ & $1 \mathrm{Min}$ & $2 \mathrm{Min}$ & $4 \mathrm{Min}$ & $8 \mathrm{Min}$ & $16 \mathrm{Min}$ \\
\hline & \multicolumn{7}{|c|}{ Experiment 1} \\
\hline $\mathbf{A}$ & 2.6 & 2.8 & 5.0 & 15.7 & 14.5 & 5.7 & 25.8 \\
\hline $\mathbf{B}$ & 3.0 & 11.2 & 3.2 & 2.4 & 2.6 & 5.2 & 3.0 \\
\hline $\mathbf{D}$ & 7.2 & 5.7 & 11.8 & 10.2 & 4.2 & 20.9 & 6.0 \\
\hline $\mathbf{E}$ & 2.8 & 4.9 & 2.9 & 2.7 & 2.5 & 2.6 & 3.0 \\
\hline $\mathbf{F}$ & 1.3 & 1.2 & 1.5 & 1.3 & 1.6 & 1.4 & 1.4 \\
\hline Mean & $\mathbf{3 . 3}$ & 4.6 & 6.2 & 5.5 & 4.3 & 7.2 & 7.1 \\
\hline SD & \pm 4.3 & \pm 8.4 & \pm 10.3 & \pm 11.0 & \pm 9.5 & \pm 12.9 & \pm 12.2 \\
\hline \multirow[t]{2}{*}{$\mathbf{N}$} & 42 & 34 & 45 & 34 & 36 & 39 & 35 \\
\hline & \multicolumn{7}{|c|}{ Experiment 2} \\
\hline G & 3.1 & 2.3 & 4.0 & 3.9 & 7.0 & 4.4 & 6.9 \\
\hline $\mathbf{H}$ & 3.2 & 3.6 & 3.6 & 6.0 & 4.7 & 11.0 & 12.3 \\
\hline $\mathbf{I}$ & 4.5 & 5.9 & 10.1 & 5.6 & 8.0 & 14.0 & 8.8 \\
\hline$J$ & 2.4 & 1.4 & 2.4 & 4.3 & 4.0 & 2.6 & 4.5 \\
\hline Mean & 3.3 & 3.3 & 5.0 & 5.0 & 5.9 & 8.0 & 8.1 \\
\hline SD & \pm 2.6 & \pm 4.0 & \pm 6.0 & \pm 3.3 & \pm 4.0 & \pm 8.6 & +5.7 \\
\hline \multirow[t]{2}{*}{$\mathbf{N}$} & 24 & 24 & 24 & 24 & 24 & 24 & 24 \\
\hline & \multicolumn{7}{|c|}{ Experiments 1 and 2} \\
\hline Mean & $\mathbf{3 . 3}$ & 4.1 & 5.8 & 5.3 & 5.0 & 7.5 & 7.5 \\
\hline SD & \pm 3.7 & \pm 7.0 & \pm 9.8 & \pm 8.6 & \pm 7.8 & \pm 11.4 & \pm 10.0 \\
\hline $\mathbf{N}$ & 66 & 58 & 69 & 58 & 60 & 63 & 59 \\
\hline
\end{tabular}

phase of gradual reduction in number of reinforced leverpresses per $\mathbf{S}+$ interval; they went immediately from the discrimination learning phase, with 31 leverpresses per $\mathrm{S}+$ period, to the testing phase.

During the testing phase, each animal was presented with a random sequence of $\mathrm{S}+$ and $\mathrm{S}-$ intervals, with the $\mathbf{S}-$ intervals varied as described above and the $\mathrm{S}+$ intervals terminating after the first leverpress. The daily sessions for both experiments lasted about $70 \mathrm{~min} /$ animal. Testing lasted 3 to 7 days for Experiment 1 and 7 to 12 days for Experiment 2. In Experiment 1, Animal B lost its electrode after 3 days of testing; Animals A, D, E, and F were tested a full 7 days. In Experiment 2, Animal $H$ lost its socket after 7 days of testing; Animals $G, I$, and $J$ were tested a full 12 days.

At the end of the experiment, all animals were sacrificed and perfused with $0.9 \%$ saline, followed by $10 \%$ formalin in $0.9 \%$ saline solution. Sections of the extracted brains were frozen and sliced at 40 microns. They were stained with cresyl violet.

\section{RESULTS}

Table 1 shows the effect of the $S-$ duration on the latency of response to the $\mathrm{S}+$ during the last 3 days of the testing phases of the two experiments. Neither the mean latencies for Experiment 1 nor those for Experiment 2, nor those for both experiments together, varied systematically with $\mathrm{S}-$ duration; the Kruskal-Wallis analyses of variance for these three groups of data all yielded nonsignificant $H$ values.

Five of the nine animals (B, E, F, G, and $J)$ showed a complete absence of lability; the latency of response to the $\mathrm{S}+$ was just as short following the long S- intervals as following the short intervals, and all the latencies were very short. There did appear to be a degree of lability in the behavior of the other four animals, but statistical tests failed to substantiate a true effect of $\mathrm{S}-$ duration, either for the four animals as a group or for any one of them individually; this is explained by the high variation of the scores for the longer $\mathrm{S}-$ periods, which reflects the "all-or-none" nature of the response following long $\mathrm{S}-$ periods.

We have evidence that the signs of lability in the behavior of Animals A and $D$ were transitory and not the result of any inherent lability of forebrain reinforcement. Immediately following the testing phase of this experiment, we used these two animals as pilot animals in the study of the insatiability of discrimination behavior maintained by ESB reinforcement. The day following testing, these animals were put into the same experimental chamber as that used for the experiment proper and left there for $48 \mathrm{~h}$, with food and water present, to see whether forebrain animals satiate on a discrimination task as they do on a CRF task. Relevant to the present experiment, we found that almost from the beginning of the session the latencies of response to $\mathrm{S}+$ were very short for both animals and remained short for many hours. The mean latencies for Animal A over the first 180 trials of this "extended" session were $1.5,1.7,1.9,2.2,2.2$, 2.9 , and $3.4 \mathrm{sec}$ for the $15-\mathrm{sec}, 30-\mathrm{sec}$, 1-min, 2-min, 4-min, 8-min, and 16-min $\mathrm{S}-$ intervals, respectively. The corresponding means for Animal D were $6.4,3.2,4.7,5.3,3.9,5.1$, and 6.2 . These observations suggest that whatever lability was present in the behavior of Animals $A$ and $D$ during the testing phase of the experiment proper was the result of incomplete learning of the discrimination problem.

The purpose of Experiment 2 was specifically to study the influence of the learning factor on lability. However, this goal was not achieved because, for some of the animals ( $\mathrm{J}$ in particular), the response latencies were very short on the first day of testing, indicating that these animals had, for the most part, already learned the discrimination before the beginning of testing, even though they were subjected to a minimal training period. Nevertheless, Animal G did show something of what was expected. Whereas the latencies following the 15-sec S - interval were consistently short after the third day of testing $(30.5,52.5,31.0,3.5,1.4,2.4,2.0$, $4.0,3.2,1.9,3.0,4.5$ were the mean latencies from the first to the last day of testing), the latencies following the 16-min S- interval remained quite long until the last 3 days of testing $(60.0,31.4,11.5,31.8,32.0,43.5$, $24.9,31.0,16.0,8.0,5.5,7.2$ were the mean latencies from the first to the last day of testing); moreover, the latencies following the 8-min $\mathrm{S}-$ periods closely paralleled those for the 16-min intervals, while those for the 30 -sec intervals paralleled those for the 15 -sec intervals. These results suggest that lability, as measured by a longer latency response following longer periods of no reinforcement during $\mathrm{S}-$, diminishes during the learning of the discrimination.

There is further evidence for this point: the difference between the latency of response following the 15-sec interval was not significantly different from the latency of response following the $16-\mathrm{min}$ interval on the last day of testing (mean for all nine animals following the 15-sec interval was 3.2 ; following the 16-min interval it was 5.8; Mann-Whitney $U$ test yielded $p>.10$ ), whereas the difference was significant on the first day of testing (means of 6.1 for the 15-sec interval and 20.2 for the 16-min interval; $U=207.5, n_{1}=33, n_{2}=33$, $\mathrm{z}=4.32, \mathrm{p}<.00005$ ).

It should be emphasized that the short invariant latencies were not the result of continual leverpressing through the $\mathrm{S}-$ periods. The well-trained animals made few, if any, leverpresses during the $\mathrm{S}-$ periods, including the 8 - and 16-min periods, and then responded immediately to the $\mathrm{S}^{+}$; the animals that performed poorly still could be seen to follow the same pattern, making fewer and fewer 
leverpresses during the $S-$ period and responding faster and faster to the $\mathrm{S}+$. The mean number (all nine animals) of leverpresses per $S-$ period, counting each $\mathrm{S}-$ period as a unit, whether long or short, was 6.6 on the first day of testing and 2.6 on the last day. For each of the nine animals, there were fewer leverpresses per $\mathrm{S}-$ interval on the last day than on the first day. These data suggest, first, that part of the learning of the discrimination consisted of a decrease in sresponding and, second, that, since the rate of responding during $S-$ was so low and in many instances equal to zero, the $\mathbf{S}-$ was an effective stimulus in stopping the animal from pressing the lever. In short, the $S+$ was controlling the leverpress response, and the $S-$ was controlling the nonresponses.

The histological examination revealed that the electrode tips were located in the region of the anterior nucleus of the hippocampus and the nucleus accumbens septi, anterior to the main portion of the lateral and the medial septal nuclei; this is the same general area as that studied by Scott (1967). Eight of the nine electrodes were either in or touching the boundary of the nucleus accumbens septi; the ninth electrode (Animal D's), which was the most posterior of the group, was located in the lateral septal nucleus, although it was within $1 \mathrm{~mm}$ of the accumbens nucleus. The response rates on the last day of CRF training, just prior to discrimination training, ranged from 14 to 37 responses $/ \mathrm{min}$, indicating that these animals were typical of animals responding for forebrain ESB reward (Olds \& Olds, 1963).

DISCUSSION

The present study shows that forebrain ESB reward can maintain successive discriminative behavior free of lability, provided the discriminative behavior is sufficiently learned. This contrasts with Scott's finding (1967) that forebrain reward did not maintain runway behavior with 15-min intertrial intervals. Perhaps the difference can be explained in terms of the task variable; perhaps forebrain reward cannot maintain runway behavior but can maintain discriminative behavior; or perhaps the difference can be accounted for by the fact that the intensity of our ESB was much higher than that of Scott's. Another possible explanation is that, while learning to run the runway may be difficult with forebrain ESB as reinforcement, the forebrain reward does not unalterably produce labile behavior; that if and when the learning is complete, the behavior will not be labile, i.e., the running speeds will be as fast following the 15-min intertrial intervals as following the short intervals. Scott himself noted that the animals showing the largest overnight decrements in running times for hypothalamic reward were those showing the weakest overall performance in the runway, which is consistent with the hypothesis that there is a learning factor influencing the degree of lability. In any case, it is clear that Scott's study cannot be taken as evidence that behavior maintained by forebrain reinforcement is inherently more labile than behavior maintained by hypothalamic reinforcement.

The absence of lability observed in the present study cannot be explained by the drive-induction theory unless the added assumption is made that the $\mathrm{S}+$, or those internal stimuli associated with the $S+$, acquires the properties of a secondary drive stimulus, with the power to arouse the drive underlying the self-stimulation behavior and, thus, to offset the process of drive decay. The results are more readily explicable in terms of the incentive model (Trowill et al, 1969). The training procedure used to establish discriminative behavior exposes the animals to periods of non reinforcement; it teaches the animals to tolerate those periods and to perform the operant response in spite of them. In other words, the procedure fixes the incentive value of the ESB reward at a lower level than does the more common CRF procedure and reduces the amount of frustration experienced during the period of nonreinforcement. However, the incentive model is not fully adequate without an added emphasis on the stimulus control of the behavior. It is not only that there is less lability in the discrimination situation than in the CRF situation, there is no lability (when learning is complete). The emphasis that the general incentive theory (Bolles, 1967) gives to the possibility that incentive motivation depends on the existence of environmental stimuli having stable associations with the goal response suggests a way in which the incentive theory of self-stimulation could be expanded in order to incorporate the facts of stimulus control.

\section{REFERENCES}

BOLLES, R. C. Theory of motivation. New York: Harper \& Row, 1967.

DEUTSCH, J. A., \& HOWARTH, C. I. Some tests of a theory of intracranial self-stimulation. Psychological Review, 1963,70, 444-460.

GALLISTEL, C. R. Electrical self-stimulation and its theoretical implications. Psychological Bulletin, $1964,61,23-34$.

GANDELMAN, R., PANKSEPP, J., \& TROWILL, J. A. The effect of lever retraction on resistance to extinction of a response rewarded with electrical stimulation of the brain. Psychonomic Science, 1968, 10,5-6.

GANDELMAN, R., \& TROWILL, J. A. The effects of chlordiazepoxide on ESB-reinforced behavior and subsequent extinction. Journal of Comparative \& Physiological Psychology, 1968, 66, 753-755.

GIBSON, W. E., REID, L. D., SOKAI, M., \& PORTER. P. B. Intracranial reinforcement compared with sugar-water reinforcement. Science, 1965, 148, $1357-1358$.

HOW ARTH, C. I., \& DEUTSCH, J. A. Drive decay: The cause of fast "extinction" of habits learned for brain stimulation. Science, 1962, 137, 35-36.

KORNBLITH, C. \& OLDS, J. T-maze learning with one trial per day using brain stimulation reinforcement. Journal of Comparative \& Physiological Psychology, $1968,66,488 \cdot 491$.

LENZER, I. I., \& FROMMER, G. P Successive sensory discriminative behavior maintained by intracranial self-stimulation reinforcement. Physiology \& Behavior, 1968, 3, 345-349.

OLDS, M. E., \& OLDS, J Approach-avoidance analysis of rat diencephalon. Journal of Comparative Neurology, 1963, 120, 259-295.

PLISKOFF, S. S., WRIGHT, J. E., \& HAWKINS, T. D. Brain stimulation as a reinforcer: Intermittent schedules. Journal of the Experimental Analysis of Behavior, $1965,8,75-88$.

SCOTT, J. W. Brain stimulation reinforcement with distributed practice: Effects of electrode locus, previous experience, and stimulus intensity. Journal of Comparative \& Physiological Psychology, 1967, 63, 175-183.

TROWILL, J. A., PANKSEPP, J., \& GANDELMAN, R. An incentive model of rewarding brain stimulation. Psychological Review, 1969, 76, 264-281. 